\title{
Characterization of Benomyl Resistance in Mycosphaerella fijiensis, Cause of Black Sigatoka of Banana, in Costa Rica
}

\author{
Ronald A. Romero and Turner B. Sutton, Department of Plant Pathology, North Carolina State University, \\ Raleigh 27695
}

\begin{abstract}
Romero, R. A., and Sutton, T. B. 1998. Characterization of benomyl resistance in Mycosphaerella fijiensis, cause of black Sigatoka of banana, in Costa Rica. Plant Dis. 82:931-934.

Sixty-eight and eighty-six percent of monoascosporic isolates of Mycosphaerella fijiensis from two banana plantations in Costa Rica, in which benomyl was used for $\approx 10$ years to control black Sigatoka, were resistant to benomyl in February and November 1994, respectively. No resistance to benomyl was detected in isolates collected during February 1994 from farms with no history of benomyl use that were located $\approx 50 \mathrm{~km}$ from the nearest banana plantations. Only $1 \%$ of isolates was resistant to benomyl in a sample taken during November 1994. In three additional banana farms where benomyl had not been used for 3 to 5 years before sampling, benomyl resistance persisted at a high frequency. Benomyl-resistant and -sensitive isolates were distributed equally throughout the range of isolate sensitivity to propiconazole, indicating no relationship between resistance to benomyl and lower sensitivity to propiconazole but double resistance to these two compounds. Five benomyl-resistant and five benomyl-sensitive isolates of M. fijiensis were inoculated to banana plants under greenhouse conditions. Benomyl-resistant isolates were more aggressive than benomyl-sensitive isolates, as determined by measures of disease severity, incubation time, and number of lesions at 40 days after inoculation.
\end{abstract}

Black Sigatoka, caused by Mycosphaerella fijiensis Morelet, is an important disease of bananas (Musa spp.) in Costa Rica and many other countries in Latin America. Losses due to black Sigatoka result from severe defoliation that reduces the weight and quality of bananas. Yields can be reduced by as much as $20 \%(2 ; \mathrm{M}$. Guzmán and R. A. Romero, unpublished data), and quality is reduced because fruit from severely diseased plants ripen prematurely during transport to market (20). Black Sigatoka is controlled primarily by alternation of protectant (e.g., mancozeb) and systemic (e.g., propiconazole or benomyl) fungicides, sprayed in oil-water emulsions $(12,19)$. However, benomyl was withdrawn from most fungicide programs for control of black Sigatoka in Costa Rica after resistance to benomyl was first detected in 1991 (1).

Resistance of M. fijiensis to benomyl was reported first in 1977 in Honduras, after 2 or 3 years of continuous use (17). Stover (18) initially reported that benomylresistant isolates were nonpathogenic, and

Corresponding author: R. A. Romero

E-mail: rromero@chiquita.com

Current address of R. A. Romero: Chiquita Brands International, Box 217-1150 La Uruca, San José, Costa Rica.

Accepted for publication 5 May 1998.

Publication no. D-1998-0615-01R

(C) 1998 The American Phytopathological Society therefore, resistance was not associated with failures in disease control. Nevertheless, Stover et al. (21) indicated later that benomyl resistance was responsible for severe black Sigatoka outbreaks in Honduras. They also reported (21) that benomyl resistance decreased within 2 years of withdrawal of the fungicide from the control program, indicating benomyl-resistant strains may be less fit than sensitive strains. However, Fullerton and Tracey (5) found a carbendazim-resistant strain from western Samoa that was both pathogenic to bananas and resistant to benomyl. They concluded that resistance to carbendazim was a major factor in failure to control black Sigatoka.

The occurrence of benomyl-resistant $M$. fijiensis in banana farms in Costa Rica has not been adequately documented, although observations and unpublished studies indicate that benomyl resistance may be widespread. Additionally, the severity of black Sigatoka increased considerably and control failures were frequent in fields with suspected benomyl-resistant pathogen populations (D. Marin, personal communication).

Following suspected widespread resistance of $M$. fijiensis to benomyl in Costa Rica, use of the ergosterol biosynthesis inhibitor fungicide propiconazole increased significantly (13). However, black Sigato$\mathrm{ka}$ in most farms continued at high levels in spite of the use of propiconazole, which is one of the most effective fungicides available for control of this disease (19).

We hypothesized that benomyl resistance and reduced sensitivity to propiconazole might be related or that double re- sistance to both propiconazole and benomyl in M. fijiensis caused unsatisfactory control of black Sigatoka. This study was conducted (i) to determine the proportion and persistence of benomyl-resistant $M$. fijiensis isolates in banana farms in Costa Rica, and (ii) to characterize the aggressiveness of benomyl-resistant and -sensitive isolates.

\section{MATERIALS AND METHODS}

Test of benomyl sensitivity. A preliminary test was conducted to determine the phenotypic expression of benomyl resistance. Five monoascosporic isolates of $M$. fijiensis were selected from two banana plantations with a history of 7 to 10 years of benomyl use, and five isolates were obtained from a banana seedling production area where fungicides had not been applied. Both areas were in Costa Rica and were sampled in 1992. Monoascosporic isolates of $M$. fijiensis from each location were obtained by discharging ascospores from leaf tissue bearing pseudothecia onto water agar and transferring hyphae from each colony to Mycophil agar (Becton Dickinson Microbiology Systems, Cockeysville, MD) (8). Dishes were incubated for 2 weeks at $20^{\circ} \mathrm{C}$ in a growth chamber under continuous cool fluorescent light, at an intensity of $90 \mu \mathrm{E} \mathrm{s}^{-1} \mathrm{~m}^{-2}$, for conidia production (8).

The sensitivity of these isolates to benomyl was determined by transferring individual colonies of each isolate with a sterile dissecting needle to $1 \mathrm{ml}$ of sterile water in a test tube and vortexing the sample for $10 \mathrm{~s}$. A drop of the conidial suspension and mycelial fragments was placed on each potato dextrose agar (PDA) dish with a sterile Pasteur pipette and distributed on the surface of the medium with a sterile glass rod. The PDA medium was amended with the following concentrations of benomyl (Benlate $50 \mathrm{OD}$ ): $0,0.1,10,20$, and $30 \mu \mathrm{g}$ a.i. $\mathrm{ml}^{-1}$. Two petri dishes were used per fungicide concentration. There were between 20 and 30 colonies of $M$. fijiensis per petri dish.

Benomyl resistance was determined by measuring the diameter of 10 colonies per petri dish at each concentration of benomyl after 7 days of incubation at $25^{\circ} \mathrm{C}$. In this test, isolates of $M$. fijiensis resistant to benomyl were able to develop colonies up to benomyl concentrations of $30 \mu \mathrm{g}$ a.i. $\mathrm{ml}^{-1}$, whereas benomyl-sensitive isolates did not grow at $0.1 \mu \mathrm{g}$ a.i. $\mathrm{ml}^{-1}$ (Table 1). Based on these results, additional monitoring of re- 
sistance to benomyl, conducted during February 1994 , was simplified by a single discriminatory dose of $5.0 \mu \mathrm{g}$ a.i. $\mathrm{ml}^{-1}$ and unamended medium as a control.

Isolates. Two samples of one hundred M. fijiensis monoascosporic isolates were collected during February and November 1994 from each of two commercial banana farms (San Pablo and Coopecariari) located on the Caribbean Coast of Costa Rica. In both farms, bananas were produced for export. Each plantation had been sprayed 6 to 8 times with benomyl from 1982 to 1992 and, since 1987, has been sprayed 8 to 10 times each year with propiconazole alternated with the fungicides mancozeb and tridemorph. A third location (San Carlos) isolated from the commercial banana farms and with no history of fungicide use was selected for collection of 100 reference isolates of $M$. fijiensis from backyard bananas during both February and November 1994. Monoascosporic isolates were obtained as described previously. The sensitivity of these isolates to propiconazole has been reported (13).

Persistence of benomyl resistance. The persistence of benomyl resistance in $M$. fijiensis was monitored (during May and November 1995 and May 1996) on three banana farms located on the Caribbean Coast of Costa Rica. Parques farm was established in 1992, and benomyl had never been applied. Bananas had been grown on the Semdel farm for more than 20 years, and benomyl was used from 1983 to 1992 to control black Sigatoka. Two populations of M. fijiensis from San Carlos and Pérez Zeledón with no history of fungicide use were included as base-line or reference populations. Forty-five monoascosporic isolates of $M$. fijiensis were collected from each farm by collecting fifteen isolates from each of three blocks of bananas ( $\approx 50$ ha each). Isolates were obtained from leaves bearing abundant pseudothecia on plants distributed along the 50-ha block of bananas, using the divisions of farms by cables and sections as reference points. The sensitivity of these isolates to benomyl was determined with a discriminatory dose of fungicide at $5 \mu \mathrm{g}$ a.i. $\mathrm{ml}^{-1}$, as previously described, and by measuring the diameter of 10 colonies per isolate after 5 days of incubation in the dark at $25^{\circ} \mathrm{C}$. Thirty isolates were collected from San Carlos and Pérez Zeledón from backyard or small banana farms; there are no large commercial banana farms at these two locations.

Test of aggressiveness of benomyl-resistant versus -sensitive isolates. Five benomyl-resistant and five benomyl-sensitive M. fijiensis isolates (Table 1) were tested for their aggressiveness, defined as the amount of disease caused on banana leaves in a given time period. Inoculum was produced as previously described (8).

One 10-week-old banana plant of cv. Grand Naine, propagated by tissue culture and $\approx 30 \mathrm{~cm}$ tall, was inoculated with each isolate. Inoculations were performed by atomizing conidial suspensions onto the abaxial surface of the three youngest expanded leaves, to the point of runoff, with an aerosol propellant atomizer (Crown SpraTool; Crown North American Professional Products, Woodstock, IL). Inoculated plants were tagged and placed inside a plastic chamber in a greenhouse. Plants in the chamber were watered three times a day for the first five consecutive days after inoculation to maintain high relative humidity $(>90 \%)$. Subsequently, high relative humidity was maintained only from 6:00 p.m. to 8:00 a.m. by watering the plants inside the plastic chamber at 6:00 p.m. The incubation period was measured as the time from inoculation until the appearance of 10 small red-brown flecks per leaf (stage 1 of black Sigatoka symptoms) (11). The number of stage 4 symptoms (black lesions clearly visible on both leaf surfaces or first spot stage [11]) 40 days after inoculation and severity of disease 50 days after inoculation, based on Stovers scale (16) modified by Gauhl (6), were used to compare the aggressiveness of benomyl-resistant and -sensitive isolates. The experiment was conducted as a completely randomized design, with three replications over time.

Analyses of data. Differences between benomyl-resistant and -sensitive isolates of M. fijiensis were distinct; therefore, no statistical analysis was necessary to separate them. The relationship between resistance to benomyl and reduced sensitivity to propiconazole was examined by constructing a frequency distribution of benomyl-sensitive and -resistant isolates and superimposing it on previously determined $50 \%$ effective concentration $\left(\mathrm{EC}_{50}\right)$ values for propiconazole (13). The distribution of beno- myl-sensitive and -resistant isolates throughout the range of $\mathrm{EC}_{50}$ values for propiconazole provided evidence of no cross-resistance between the two fungicides.

Analysis of variance and a least significant difference test (SAS version 6.01. SAS Institute Inc., Cary, NC) were used to compare the aggressiveness of benomylresistant and -sensitive isolates. Differences within each group of isolates were tested similarly.

\section{RESULTS}

Characterization of resistance. The percentage of M. fijiensis isolates from populations in San Pablo and Coopecariari with resistance to benomyl was higher than the percentage of resistant isolates found in San Carlos in February and November 1994 (Table 2). Benomyl resistance was not found in San Carlos in February 1994, but $1 \%$ of the population (one isolate) was resistant to benomyl in November 1994.

The distribution of benomyl-resistant and -sensitive isolates according to their $\mathrm{EC}_{50}$ values for propiconazole showed that both benomyl-resistant and -sensitive isolates were distributed over the entire range of sensitivity to propiconazole, in both the February and November samples (Fig. 1).

Benomyl-resistant $M$. fijiensis isolates were still present in all samples taken from San Pablo during May and November 1995 and May 1996, despite the fact that no benomyl had been used in the control programs since 1992 (Table 3). In Parques farm, which was a relatively new farm where benomyl had not been used, the proportion of benomyl-resistant isolates increased considerably from May to November 1995 and remained high in the last sample taken during May 1996. A high level of benomyl

Table 2. Percentage of benomyl-resistant isolates of Mycosphaerella fijiensis from three populations $^{\mathrm{y}}$ in Costa Rica at two sampling times

\begin{tabular}{llll}
\hline $\begin{array}{l}\text { Date of } \\
\text { sampling }\end{array}$ & $\begin{array}{c}\text { San } \\
\text { Carlos }\end{array}$ & $\begin{array}{c}\text { San } \\
\text { Pablo }\end{array}$ & $\begin{array}{c}\text { Coope- } \\
\text { cariari }\end{array}$ \\
\hline Feb. 1994 & $0(100)^{\mathrm{z}}$ & $80(87)$ & $74(81)$ \\
Nov. 1994 & $1(72)$ & $92(90)$ & $61(83)$ \\
\hline
\end{tabular}

y Populations from San Pablo and Coopecariari had a history of 10 years of benomyl and 7 years of propiconazole use, respectively.

${ }^{\mathrm{z}}$ Numbers in parentheses indicate total number of isolates tested.

Table 1. Phenotypic expression of sensitivity of isolates of Mycosphaerella fijiensis from Costa Rica to benomyl

\begin{tabular}{|c|c|c|c|c|c|c|c|c|c|c|}
\hline \multirow{3}{*}{$\begin{array}{l}\text { Benomyl } \\
\text { concentration } \\
\left(\boldsymbol{\mu g} \text { a.i. } \mathbf{m l}^{-1}\right)\end{array}$} & \multicolumn{10}{|c|}{ Colony diameter $(\mu \mathrm{m})$} \\
\hline & \multicolumn{5}{|c|}{ Benomyl resistant } & \multicolumn{5}{|c|}{ Benomyl sensitive } \\
\hline & CRB1 & CRB2 & CRB3 & CRB4 & CRB5 & CRMI & CRMJ & CRGE & CRGF & CR12 \\
\hline 0 & $1,121^{\mathrm{z}}$ & 1,270 & 1,065 & 1,053 & 1,321 & 1,327 & 1,295 & 1,095 & 1,025 & 1,118 \\
\hline 0.1 & 1,105 & 1,247 & 975 & 881 & 1,392 & 0 & 0 & 0 & 0 & 0 \\
\hline 10.0 & 1,032 & 1,135 & 723 & 647 & 1,217 & 0 & 0 & 0 & 0 & 0 \\
\hline 20.0 & 338 & 437 & 200 & 145 & 353 & 0 & 0 & 0 & 0 & 0 \\
\hline 30.0 & 343 & 353 & 0 & 123 & 398 & 0 & 0 & 0 & 0 & 0 \\
\hline
\end{tabular}

${ }^{\mathrm{z}}$ Colony diameters were measured with a microscope on amended potato dextrose agar after 7 days of incubation at $25^{\circ} \mathrm{C}$. Values correspond to the mean of 10 colonies from each of 2 petri dishes. 
resistance also was observed in Semdel at all sampling times. No benomyl-resistant isolates were found in San Carlos or Pérez Zeledón.

Test of aggressiveness of benomyl-resistant isolates. Benomyl-resistant isolates had shorter incubation periods compared to benomyl-sensitive isolates and caused a higher number of stage 4 symptoms and greater disease severity on banana leaves compared to benomyl-sensitive isolates $(P=$ 0.001; Table 4). No statistical differences for any of the variables were observed within the benomyl-resistant and -sensitive groups of isolates.

\section{DISCUSSION}

This study confirms that a high level of benomyl resistance is present in the populations of $M$. fijiensis in bananas in Costa Rica and that resistant isolates of this pathogen have persisted in the absence of benomyl. The persistence of a large population that is benomyl-resistant several years after the withdrawal of benomyl from the control programs in Costa Rica differs from previous reports from Honduras that indi-
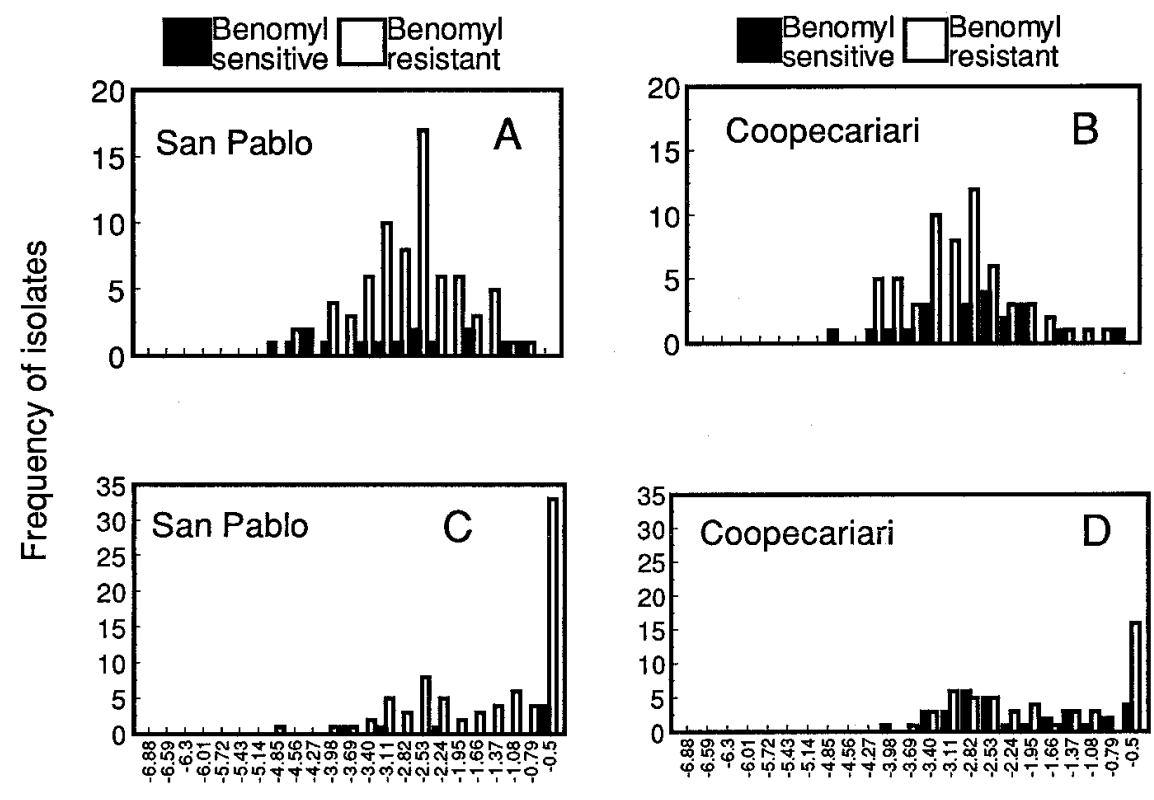

cated benomyl resistance decreased within 2 years of the withdrawal of the fungicide (21). Therefore, we recommend that growers monitor the sensitivity of $M$. fijiensis populations to benomyl before considering any use of benomyl in bananas in Costa Rica, regardless of the number of years the product has been discontinued from control programs.

Both benomyl-resistant and -sensitive isolates were distributed throughout the range of $\mathrm{EC}_{50}$ values for propiconazole in the San Pablo and Coopecariari farms (Fig. 1), which indicates that no cross-resistance exists between benomyl and propiconazole and agrees with the differences in the mechanisms of fungal resistance described for propiconazole (10) and benomyl (3). Thus, the $M$. fijiensis populations in San Pablo and Coopecariari are composed of a high proportion of isolates with double resistance to the most effective fungicides available for control of black Sigatoka: benomyl and propiconazole. Double resistance is likely to occur in many other farms in Costa Rica where benomyl and propiconazole no longer provide satisfactory control, because most

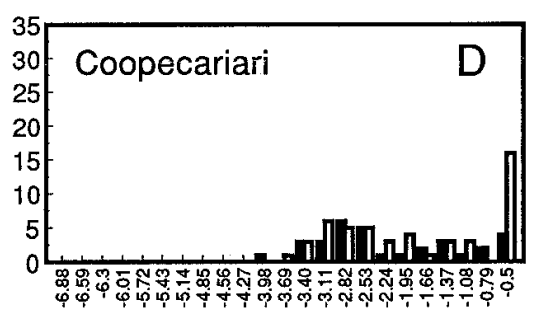

$\mathrm{EC}_{50}(\mathrm{Ln}$ of $\mu \mathrm{g} / \mathrm{ml})$ to propiconazole

Fig. 1. Frequency distribution of benomyl-sensitive and -resistant isolates of Mycosphaerella fijiensis, based on their $50 \%$ effective concentration $\left(\mathrm{EC}_{50}\right)$ value for propiconazole. Isolates were collected during (A and B) February and (C and D) November 1994.

Table 3. Frequency of benomyl resistance in Mycosphaerella fijiensis isolates from three banana farms (Parques, San Pablo, and Semdel) and two sites with no history of benomyl use (San Carlos and Pérez Zeledón) in Costa Rica at three sampling times

\begin{tabular}{lccccc}
\hline $\begin{array}{l}\text { Date of } \\
\text { sampling }\end{array}$ & Parques $^{\mathbf{z}}$ & San Pablo & Semdel & San Carlos & $\begin{array}{c}\text { Pérez } \\
\text { Zeledón }\end{array}$ \\
\hline May 1995 & 42 & 69 & 44 & 0 & 0 \\
Nov. 1995 & 100 & 97 & 69 & 0 & 0 \\
May 1996 & 81 & 84 & 66 & 0 & 0 \\
\hline
\end{tabular}

${ }^{\mathrm{z}}$ Forty-five isolates were collected on each sampling date from Parques, San Pablo, and Semdel, and thirty isolates were collected on each sampling date from San Carlos and Pérez Zeledón. banana farms are concentrated in a small geographic region on the Caribbean Coast, and the fungicide programs for the control of black Sigatoka among farms have been similar.

Phenotypic expression of M. fijiensis resistance to benomyl appears to be monogenically controlled, because isolates that were sensitive did not grow at concentrations of benomyl greater than $0.1 \mu \mathrm{g}$ a.i. $\mathrm{ml}^{-1}$, whereas isolates that were resistant grew at concentrations of the fungicide greater than $10 \mu \mathrm{g}$ a.i. $\mathrm{ml}^{-1}$. Monogenic control of resistance to benzimidazoles occurs in many pathogens $(3,4,7,9,14)$. In populations of M. fijiensis in bananas in Costa Rica, benomyl resistance has persisted. The San Pablo and Semdel farms showed high frequencies of resistant isolates 4 years after benomyl was withdrawn from control programs. The presence of benomyl resistance in Parques farm, despite no previous applications of benzimidazole fungicides, is believed to have been due to immigration of ascospores dispersed by wind from neighboring farms.

The greater aggressiveness of benomylresistant compared to benomyl-sensitive isolates and the persistence of benomyl-resistant isolates indicate there is no apparent cost in fitness associated with the acquisition of a gene for resistance to benomyl by $M$. fijiensis. However this conclusion differs from that of Smith (15) who suggested that strains of $M$. fijiensis resistant to benomyl are not as competitive as wildtype strains.

Although benomyl-resistant strains were more aggressive than benomyl-sensitive isolates, the former were obtained from fields with a history of fungicide use, whereas sensitive strains were collected from fields with no history of fungicide use. Thus, it is possible that the greater aggressiveness of the benomyl-resistant isolates could be a reflection of the effect of fungicide treatments on genes in the fungus population

Table 4. Aggressiveness of five benomyl-resistant (resistant) and five benomyl-sensitive (sensitive) isolates of Mycosphaerella fijiensis on banana cv. Grand Naine inoculated in a greenhouse

\begin{tabular}{lccc}
\hline Isolate & $\begin{array}{c}\text { Incubation } \\
\text { (days) }\end{array}$ & $\begin{array}{c}\text { No. of } \\
\text { stage } \mathbf{4} \\
\text { lesions }^{\mathbf{x}}\end{array}$ & Severity $^{\mathbf{y}}$ \\
\hline Resistant & $18.9 \mathrm{~b}^{\mathrm{z}}$ & $16.2 \mathrm{a}$ & $3.1 \mathrm{a}$ \\
Sensitive & $20.5 \mathrm{a}$ & $4.3 \mathrm{~b}$ & $1.7 \mathrm{~b}$ \\
\hline
\end{tabular}

${ }^{x}$ Number of lesions at 40 days after inoculation. Stage 4 is the first spot stage characterized by black color visible on both sides of the leaf (11).

${ }^{y}$ Disease severity based on Stovers scale (14), modified by Gauhl (6), from 0 to 6 , where $0=$ no symptoms and $6=$ more than $50 \%$ of the leaf area affected.

${ }^{z}$ Values with different letters in a column correspond to significant differences $(P=0.001)$ according to analysis of variance and a least significant difference test. 
other than the effects associated with the acquisition of resistance.

The fitness of isolates that are resistant to benomyl and also highly resistant to propiconazole needs to be investigated, because the isolates we used in our test of aggressiveness had relatively low $\mathrm{EC}_{50}$ values for propiconazole (data not shown), compared to the very high $\mathrm{EC}_{50}$ values of most isolates found in the populations from San Pablo, Coopecariari, Semdel, and Parques (13), which also were resistant to benomyl.

\section{ACKNOWLEDGMENTS}

We thank L. R. Pope and A. Hurtado for technical assistance.

\section{LITERATURE CITED}

1. Anonymous. 1993. FRAC, SBI Working Group Bananas. Conclusions and Recommendations. 3rd Meeting. Orlando, FL.

2. Chuang, T. Y. 1981. Chemical control of banana leaf spot caused by Mycosphaerella fijiensis var. difformis. Plant Prot. Bull. (Taiwan) 23:87-94.

3. Davidse, L. C. 1988. Benzimidazole fungicides: Mechanism of action and resistance. Pages 25-27 in: Fungicide Resistance in North America. C. J. Delp, ed. The American Phytopathological Society, St. Paul, MN.

4. Eckert, J. W. 1988. Dynamics of benzimidazole-resistant penicillia in the development of postharvest decays of citrus and pome fruits. Pages 31-39 in: Fungicide Resistance in North America. C. J. Delp, ed. The American Phytopathological Society, St. Paul, MN.
5. Fullerton, R. A., and Tracey, G. M. 1984. Tolerance of Mycosphaerella fijiensis to benomyl and carbendazim in the Pacific Islands. Trop. Agric. (Trinidad) 61:132-136.

6. Gauhl, F. 1989. Untersuchungen zur Epidemiologie und Ökologie der schwarzen Sigatoka Krankheit (Mycosphaerella fijiensis Morelet) an Kockbonanen (Musa sp.) in Costa Rica. $\mathrm{Ph} . \mathrm{D}$. thesis. Universität Göttingen, Göttingen, Germany.

7. Georgopoulus, S. G. 1982. Genetical and biochemical background of fungicide resistance. Pages 46-52 in: Fungicide Resistance in Crop Protection. J. Dekker and S. G. Georgopoulus, eds. Pudoc Scientific Publishers, Wageningen, Netherlands.

8. Jacome, L., and Schuh, W. 1992. Effects of leaf wetness duration and temperature on development of black Sigatoka disease on banana infected by Mycosphaerella fijiensis var. difformis. Phytopathology 82:515-520.

9. Koenraadt, H., Somerville, S., and Jones, A. L. 1992. Characterization of mutations in the betatubulin gene of benomyl-resistant field strains of Venturia inaequalis and other plant pathogenic fungi. Phytopathology 82:1348-1354.

10. Köller, W. 1988. Sterol demethylation inhibitors: Mechanism of action and resistance. Pages 79-88 in: Fungicide Resistance in North America. C. J. Delp, ed. The American Phytopathological Society, St. Paul, MN.

11. Meredith, D., and Lawrence, J. 1969. Black leaf streak disease of bananas (Mycosphaerella fijiensis): Symptoms of the disease in Hawaii and notes on the conidial state of the causal fungus. Trans. Br. Mycol. Soc. 52:459476.

12. Romero, R., and Cubero, E. 1987. Instructivo sobre el combate de la Sigatoka negra del banano. ASBANA (Costa Rica) Boletin 3.

13. Romero, R. A., and Sutton, T. B. 1997. Sensitivity of Mycosphaerella fijiensis, causal agent of black Sigatoka of bananas, to propiconazole. Phytopathology 87:96-100.

14. Shabi, E., Katan, T., and Marton, K. 1983. Inheritance of resistance to benomyl in isolates of Venturia inaequalis from Israel. Plant Pathol. 32:207-212.

15. Smith, C. M. 1988. History of benzimidazole use and resistance. Pages 23-24 in: Fungicide Resistance in North America. C. J. Delp, ed. The American Phytopathological Society, St Paul, MN.

16. Stover, R. H. 1971. A proposed international scale for estimating intensity of Banana Leaf Spot. Trop. Agric. (Trinidad) 48:185-196.

17. Stover, R. H. 1977. Behavior of benomyl tolerant strains of the black Sigatoka pathogen in the field. Proc. Am. Phytopathol. Soc. 4:180181.

18. Stover, R. H. 1977. Extranuclear inherited tolerance to benomyl in Mycosphaerella fijiensis var. difformis. Trans. Br. Mycol. Soc. 72:518519.

19. Stover, R. H. 1990. Sigatoka leaf spot: Thirty years of changing control strategies. Pages 66-74 in: Sigatoka leaf spot diseases of bananas. R. A. Fullerton and R. H. Stover, eds. Proc. Int. Workshop. International Network for the Improvement of Banana and Plantain, Montpellier, France.

20. Stover, R. H. 1990. Sigatoka leaf spots of bananas and plantains. Plant Dis. 64:750-756.

21. Stover, R. H., Slabaugh, W. R., and Grove, M. D. 1978. Effect of chlorothalonil on a severe outbreak of banana leaf spot caused by benomyl tolerant Mycosphaerella fijiensis var. difformis. Phytopathol. Newsl. 12:268. 